\title{
MEMAHAMI KOMUNIKASI BEDA BUDAYA STUDI KASUS PADA PROSES ADAPTASI KAUM EXPATRIATE EROPA DAN AUSTRALIA TERHADAP MASYARAKAT LOKAL KOTA SEMARANG
}

\author{
Martina Dwi Hardani \\ (martinadwihardani696@gmail.com) \\ (Mahasiswa S 1 Program Studi Ilmu Komunikasi Universitas Semarang)
}

\begin{abstract}
The research aims to understand how to communicate between culture of expatriate cross cultural adaptation process to local society in Semarang. Those, can seen from communing meaning process by language, culture, and lifestyle.

The main theories used in this research is Interactional Symbolic Theory. There are three base of principal in Interactional Symbolic Theory by Blummer involve meaning, language, and thought. This permis leads to conclusion about persons self and their socialization to bigger community.

Research Methodology used was qualitative descriptive is there search method that seeks to describe and interpret the object as it is, by describing systematically the facts and characteristics of the object studied properly. Data sampling using a purposive sampling that is based on the theoretical basis used, but it can grow as needed and steadiness in obtaining data. Sources studied are the expatriates who live in the city of Semarang. Informants were interviewed were three people who joined in Semarang Expatriate Community who have more than 3 years and experiencing the cross culture.

This research concluded that cross culture communication in adaptation process of the expatriate to Semarang community vulnerable on problems because of cultural differences, patterns of thought, behavior, and lifestyle habits so that anxiety and uncertainty lead to misunderstandings, and differences in communicating meaning. Therefore, in the process adaptation needs a high sense of empathy and good management meaning and mutual respecting between different cultures to create a good living in different cultural society.
\end{abstract}

Kata Kunci : Komunikasi budaya, Expatriate, dan Hambatan

\section{Pendahuluan}

Indonesia mempunyai banyak pulau, keanekaragaman budaya, warisan kebudayaan,tempat-tempat wisata yang indah yang bisa dikenalkan kepada dunia.Banyak tempat-tempat atau pulau-pulau yang menarik minat warga asing untuk datang. Baik itu untuk sekedar liburan dan menikmati beragam ke exotis-an panorama alam di bumi Indonesia, untuk bekerja, dan bahkan menetap untuk membuka peluang usaha di Indonesia. Apalagi di era globalisasi sekarang ini peredaran bisnis lintas Negara berjalan seperti tidak ada batasan.Sistem perekonomian banyak dikendalikan oleh masyarakat asing yang berdomisili di Indonesia.

Kota-kota besar masih mendominasi hadirnya warga asing yang menetap untuk bekerja.Karena di kota-kota besar inilah proses perdagangan, pertukaran informasi, dan kegiatan dari globalisasi berjalan. 
Seperti contohnya di Jakarta, ada banyak kaum expatriate yang bisa ditemui disetiap sudut. Menurut Kamus Besar Bahasa Indonesia, Expatriate adalah seseorang yang berpindah domisili atau Negara atau bahkan mengubah kewarganegaraannya.

Kota lain yang menjadi tujuan para expatriate untuk melancarkan bisnis globalnya adalah Semarang. Sebagai ibukota dari Jawa Tengah, Semarang merupakan centra Industri yang banyak menarik minat dan mendatangkan warga-warga asing. Warga Eropa dan Africa banyak mendiami Kota Semarang. Sebagai Kota Industri, Semarang menghasilkan komoditas export seperti kayu untuk meubel,dangarment,yang paling diminati oleh kaum-kaum expat ini. Demikian suburnya Kota Semarang sebagai industri untuk kayu dan garment ( baju seragam, baju bola, jaket ) sehingga warga asing ini berani membuka peluang usaha dan masyarakat lokal menjadi pegawainya (buruh pabrik). Dan tidak sedikit dari mereka yang kemudian menikah dan menjadi warga Negara Indonesia.

Mengingat ada perbedaan kebudayaan yang menonjol antara Indonesia dan warga Asing, tentunya akan menimbulkan berbagai kesulitankesulitan seperti cara berkomunikasi, cara berperilaku, cara dan pola hidup,.Menyatukan antara budaya asing ke dalam budaya Timur ala Indonesia, Jawa khusunya. Bagaimana warga asing ini bersusah payah berkomunikasi karena kendala bahasa dan latar belakang kebudayaan serta budaya yang berbeda.

Kebudayaan sendiri menurut Djoko Widaghdo (1994) dalam bukunya yang berjudul Ilmu Budaya Dasar memberikan pembedaan pengertian budaya dan kebudayaan. Dengan mengartikan budaya sebagai daya dari budi yang berupa cipta, rasa, dan karsa. Sedangkan kebudayaan diartikan sebagai hasil dari cipta, karsa,dan rasa tersebut. Dalam literatur lain dikatakan bahwa kebudayaan adalah seluruh cara kehidupan dari masyarakat yang manapun dan tidak hanya mengenai sebagian dari cara hidup itu yaitu bagian yang oleh masyarakat dianggap lebih tinggi atau lebih diinginkan

Ada contoh kecil dan simple seperti bule Belanda sebagai pengusaha rotan yang sedikit sedikit bisa berbahasa Indonesia dengan karyawan bagian produksinya "Mister..misterrr...semua pesanan sudah saya terima, tapi saya bingung untuk ukurannya mau yang besar apa tanggung??" kata karyawannya. Si bule bingung dan bertanya "What the meaning of tanggung bapak? Ada bahasa lainnya??" Alhasil karyawan yang kesemuanya penduduk setempat dengan mayoritas pendidikan rendah karena mereka hanya karyawan produksi atau buruh bahasa kasarnya, dibuat bingung karena tidak mengerti harus menjawab apa. Keadaan yang disebut misscommunications seperti ini yang menyebabkan

kesalahpahaman, rasa takut, dan bahkan ketidakpastian (uncertainty).

Di dalam kehidupan percintaan, ketika bule Italy memiliki hubungan asmara atau indepth relationship dengan wanita lokal Semarang, suku Jawa dengan segala macam tata cara, adat istiadat, agama yang kuat dan sopan santun yang tinggi. Ketika bule mengucapkan kata kasar dalam bahasa sehari-harinya di Negaranya dipergunakan untuk guyonan atau joke atau becandaan biasa. " Vaffancullo"yang dalam bahasa Italy selalu diucapkan untuk mengungkapkan kekecewaan atau umpatan atau makian untuk lebih kasarnya seperti "Shit" atau "Damn”.Dan si perempuan Jawa pun 
menangis karena merasa harga dirinya diinjak-injak dengan ucapan kasar seperti itu.Ini merupakan fenomena antara perbedaan bahasa yang terjadi antara masyarakat lokal dan warga asing.Inilah yang dinamakan Komunikasi antarbudaya, yaitu:

"ketika dalam satu komunikasi melibatkan interaksi antara orangorang yang persepsi dan budaya dan system simbolnya cukup berbeda dalam suatu komunikasi" (Larry A. Samovar, 2000: 59).

Budaya yang paling terkenal yang dibawa oleh warga asing adalah tentang pola hidup atau gaya hidup "lifestyle" yakni menganut gaya hidup bebas "free-lifestyle". Menurut stereotype masyarakat Indonesia bahwa orang barat memiliki budaya hidup bebas, free-lifestyle yang cenderung merusak dan bertentangan dengan norma-norma agama dan adat istiadat ke timuran yang berlaku di Indonesia. Stereotype sendiri adalah pola atau cara pandang seseorang terhadap sesuatu secara subyektife dengan hanya melihat berdasarkan kelompok tertentu. Contohnya adalah di luar negeri dilegalkan hidup satu rumah tanpa adanya keterikatan pernikahan antara pria dan wanita yang mereka sebut sebagai living togetheratau bahasa Indonesia yang lebih familiar kita sebut sebagai "kumpul kebo". Dalam pola hidup orang barat hidup bersama legal untuk punya anak dan bahkan sampai tua sampai ke turunan selanjutnya.

Ketika pertama kali berada didalam sebuah linkungan baru atau masyarakat dengan kebudayaan yang jauh berbeda maka muncul ketidakpastian, kecemasan, dan kesalahpahaman persepsi pasti terjadi di hampir semua individu. Permasalahan yang dapat diidentifikasi dalam penelitian ini adalah "bagaimana cara komunikasi antar budaya dalam proses adaptasi warga asing (kaum expatriate) dengan masyarakat lokal di Kota Semarang? “

\section{Tinjauan Pustaka \\ Fenomenologi}

Penelitian kualitatif adalah penelitian yang mendasarkan pada kesadaran atau cara subyek dalam memahami obyek dan peristiwa yang didasari oleh pengalaman. Sedangkan pendekatan yang digunakan adalah pendekatan fenomenologi yaitu pendekatan yang mencoba mengungkapkan realita melalui pengalaman alamiah seseorang yang diciptakan melalui penggunakan bahasa dalam kehidupan seharihari.Pendekatan fenomenologi berusaha memahami dan menghimpun data, menganalisis dan membuat kesimpulan terhadap suatu fenomena, yang ditekankan kepada fenomenologi adalah aspek subyektif dari perilaku seseorang. Fenomenologi berusaha masuk kedalam dunia konseptual para subyek yang diteliti sedemikian rupa sehingga mereka mengerti apa dan bagaimana suatu pengertian yang dikembangkan oleh mereka sekitar peristiwa dalam kehidupan sehari-hari. (Meleong, 2001 :9)

Paradigma fenomenologi, merupakan studi tentang pengetahuan yang berasal dari kesadaran, atau cara kita sampai pada pemahaman tentang obyek-obyek atau kejadian-kejadian yang secara sadar kita alami. Fenomonologi melihat obyek-obyek dan peristiwa-peristiwa dari perspektife seseorang sebagai perceiver (Turnomo Rahardjo, 2005:44)

\section{Interaksi Simbolik}

Drs. Gunawan Witjaksana, MSi dalam bukunya Pokok-Pokok Pikiran dalam 
Metodologi Penelitian Komunikasi Kualitatif mengatakan; Sejalan dengan pendekatan Fenomenologis, dasar pandangan atas interaksi simbolik adalah bahwa pengalaman manusia diperoleh lewat interpretasi. Obyek, situasi, orang dan peristiwa, tidak memiliki maknanya sendiri.Adanya atau terjadinya makna dari berbagai hal tersebut karena diberi berdasarkan interpretasi dari orang yang terlibat. Selanjutnya interpretasikan bukanlah kerja otonom dan juga tidak ditentukan oleh suatu kekuatan khusus manusia ataupun yang lain. Di dalam melakukan interpretasikan seseorang dapat menggunakan bantuan orang lain, dalam kehidupan serta aktivitasnya sehari-hari, baik dengan orang-orang di masa lampaunya yang berbeda-beda.

\section{Hambatan Komunikasi Budaya}

Hambatan komunikasi atau yang juga dikenal sebagai communication barrier adalah segala sesuatu yang menjadi penghalang untuk terjadinya komunikasi yang efektif (Chaney dan Martin, 2004: 11). Menurut Chaney dan Martin hambatan dalam komunikasi antar budaya dibedakan menjadi dua jenis besar yaitu hambatan diatas air (above waterline) dan bawah air (below waterline). Faktor-faktor hambatan komunikasi antar budaya yang berada dibawah air (below waterline) adalah faktor-faktor yang membentuk perilaku atau sikap seseorang, hambatan jenis ini cukup sulit untuk dilihat atau diperhatikan. Jenis-jenis hambatan yang termasuk dalam below waterline adalah persepsi (perceptions), norma (norms), stereotip (stereotypes), filosofi bisnis (business philosophy), aturan (rules), jaringan (networks), nilai (values), dan grup cabang (subcultures group).

\section{Komunikasi Antar Budaya}

Menurut Charley H.Dood, Komunikasi antarbudaya meliputi komunikasi yang melibatkan peserta komunikasi yang mewakili pribadi, antar pribadi,dan kelompok, dengan tekanan pada perbedaan latar belakang kebudayaan yang mempengaruhi perilaku komunikasi para peserta. (Dood, 1991 : 5). Pengertian-pengertian antar budaya tersebut membenarkan sebuah hipotesis proses komunikasi antarbudaya, bahwa semakin besar derajat perbedaan antarbudaya maka semakin besar pula untuk kehilangan peluang untuk merumuskan suatu tingkat kepastian sebuah komunikasi yang efektif. Hal ini disebabkan karena ketika komunikasi antarbudaya terjadi, pertukaran pesan terjadi dari pelaku yang berbeda kebudayaan, maka terdapat pula perbedaan-perbedaan dalam sejumlah hal yaitu derajat pengetahuan, kesulitan dalam menciptakan persepsi, derajat ambiguitas, hal-hal yang mungkin tidak bermanfaat, dan bahkan suasana yang tidak bersahabat.

\section{Metodologi Penelitian}

Penelitian ini, menggunakan pendekatan model analisis deskriptif kualitatif. Metode analisis deskriptif kualitatif yang dilakukan pada penelitian ini dimaksud untuk memungkinkan sesorang membuat pengertian tentang berbagai hal yang dialaminya. Seperti yang dinyatakan Spilgelberg (dalam Gunawan Witjakana, 2005) deskripsi kualitatif mempersyaratkan suatu usaha dengan keterbukaan piker untuk merumuskan subjek yang sedang diteliti.

Metode deskriptif pada hakekatnya adalah mencari teori, bukan menguji teori. Metode ini menitikberatkan pada observasi dan suasana alamiah. Peneliti bertindak sebagai pengamat. Ia hanya membuat 
kategori pelaku, mengamati gejala dan mencatatnya dalam buku observasi. Dengan suasana alamiah berarti peneliti terjun ke lapangan. Ia tidak berusaha memanipulasi variabel karena kehadirannya mungkin mempengaruhi gejala, peneliti harus berusaha memperkecil pengaruh tersebut (Lexy. J. Moleong, 2002: 34).

Jenis data dalam penelitian ini dibagi dalam bentuk data primer dan data sekunder. Data Primer adalah data yang diperoleh secara kasat mata dari narasumber melalui wawancara langsung. Data primer yang diperoleh dalam penelitian ini adalah hasil pengamatan secara langsung dengan informan berupa hasil wawancara. Sumber data dalam penelitian ini adalah informan atau narasumber yaitu expatriate yang sudah lebih dari tiga tahun menetap di Semarang dan telah mengalami perubahan budaya. Usia dipersempit dari 30-50 tahun, laki-laki dan tergabung dalam Semarang Expatriate Community.

Menurut Patton (dalam Gunawan Witjaksana, 2005), purposive sumpling adalah peneliti mendasarkan pada landasan teori yang digunakannya, keinginan pribadi, karakteristik empiris yang dihadapi karena itu pemilihan sampling lebih cenderung didasarkan pada penguasaan/pemilikan informasi terkait dengan penelitian yang sedang peneliti lakukan bahkan dalam pelaksanaan dan pengumpulan informan dapat berkembang sesuai dengan kebutuhan dan kemantapan peneliti dalam memperoleh data. Dalam penelitian ini, peneliti membatasi informan yang akan digali informasinya. Karakter informan yang dijadikan sampel dalam penelitian ini adalah:

- Expatriate yang tinggal di Semarang tergabung dalam Semarang Expatriate Community.
- Expatriate berjenis kelamin laki-laki

- Expatriate berumur antara 30-50 tahun

- Expatriate yang lebih dari 3 tahun tinggal di Semarang dan telah mengalami dampak dari crossculture

- Expatriate yang memiliki interaksi komunikasi dengan masyarakat lokal Semarang.

Pengumpulan data adalah suatu proses pengadaan data primer untuk keperluan penelitian. Dalam penelitian ini, pengumpulan data akan dilakukan langsung oleh peneliti dalam situasi yang sesungguhnya. Teknik pengumpulan data dalam penelitian ini yang digunakan adalah data dokumentasi, wawancara mendalam yang berhubungan dengan data yang diperlukan dan observasi.

Menurut Lexy J. Moleong (2002), analisis data adalah proses mengorganisasikan dari mengurutkan data ke dalam pola, kategori dan satuan uraian dasar, sehingga dapat ditemukan tema dan dapat dirumuskan hipotesis kerja seperti yang disarankan oleh data.

Menurut Whitney, metode deskriptif kualitatif adalah pencarian fakta dengan interpretasi yang tepat. Penelitian deskriptif kualitatif mempelajari masalah-masalah dalam masyarakat, serta tata cara yang berlaku dalam masyarakat dan situasi-situasi tertentu, terbentuk tentang hubungan, kegiatan-kegiatan, sikap-sikap, pandangan-pandangan, proses-proses yang sedang berlangsung, dan pengaruh-pengaruh dari situasi fenomena (Nazir, 2003: 193).

Teknik analisis data dalam penelitian adalah setelah melalui wawancara mendalam, observasi, dan data-data melalui foto-foto dokumentasi yang berkaitan, kemudian data-data tersebut dikelola kembali untuk 
menemukan dugaan sementara. Dugaan sementara akan digunakan untuk menemukan hasil akhir setelah dikelola.

\section{Hasil dan Pembahasan}

Ada pola komunikasi beda budaya yang menarik untuk diketahui dari ketiga narasumber. Pola tersebut tentunya berbeda satu sama lain karena perbedaan latar belakang masingmasing narasumber, yaitu Marco Cisilino dari Codroipo, Italia, Ilja Kasselar dari Belanda, dan Antonio Giussepe dari Sydney, Australia.

Marco Cisilino adalah seorang kebangsaan Italy yang telah 3 tahun menetap di Kota Semarang yang mana sebelumnya telah berkeliling Indonesia dari semenjak tahun 2007. Pria kelahiran 02 Februari 1974 berasal dari kota kecil bernama Codroipo, Udine Italy. Rasa takut, aneh dan tidak nyaman pertama kali yang dirasakan ketika berinteraksi dengan masyarakat lokal Semarang. Akan tetapi kata Marco, semua bisa berjalan bagus ketika saling pengertian and don't be stranger.

Marco juga bercerita tentang pengalamannya selama di Semarang, tentang kebiasaannya ketika di Italy dan kebiasaan orang barat yang suka berjalan kaki. Di Semarang berjalan kaki sendirian di siang hari akan terlihat seperti aneh dan semua orang lokal melihatnya aneh, tertawa dan berbicara dalam bahasa Jawa yang dia tidak mengerti. Hal seperti ini menimbulkan kecemasan, kebingungan, rasa tidak nyaman dalam diri Marco. Pengalamanpengalaman sehari hari yang dialami oleh Marco ini dijadikan pelajaran apakah kebiasaan-kebiasaanya bisa diterima di masyarakat Semarang atau tidak. Sekiranya itu bisa diterima maka dia akan tetap melakukannya atau meski tidak maka dia akan menghilangkan kebiasaan itu selama di Semarang. Yang penting ada rasa saling menghormati dengan masyarakat lokal itu yang paling baik katanya. Selama dia tidak mengganggu dan menyakiti orang lain dia masih tetap bisa melakukan dan menerapkan kebiasaan-kebiasaanya di Semarang.

Narasumber berikutnya mengemukakan hal yang sedikit berbeda. Ilja Kasselar adalah pria kelahiran Belanda, 10 Maret 1976. Dari tahun 2005 sudah menetap di Semarang yang mana sebelumnya sudah tinggal di Jakarta dari tahun 2000.Jadi tidak heran kalau Ilja sangat lancar berbahasa Indonesia. Ilja adalah seorang pengusaha furniture. Menurut Ilja halhal mendasar yang tidak bisa dilakukan di Semarang adalah tentang gaya hidup bebas yang dianut oleh masyarakat Eropa kebanyakan. Free sex, living together, narkoba, alcohol, party, hidup cuek dan tidak aware dengan lingkungan sekitar.

Terkait hal ini Ilja mengatakan:

"Sebenarnya tidak semua masyarakat Eropa melalukan free sex, hubungan sejenis, living together, narkoba, alcohol... tergantung pribadi masingmasing juga... itu hanya stereotype orang-orang di Asia saja..."

Komunikasi merupakan hal yang sangat vital dalam proses interaksi dengan masyarakat sosial. Pada awalnya Ilja merasa kaget, cemas dan seperti orang aneh yang tidak tahu apaapa dilingkungan baru. Tapi dengan belajar dan berkomunikasi yang baik maka semua bisa diatasi.Pengalaman menjadikan sebuah pelajaran kata Ilja.

Informan yang selanjutnya bernama Antonio Giussepe dari Sidney, Australia. Pria keturunan latin ini bisa dibilang sukses dalam usianya yang masih muda. Kelahiran Sidney, Australia pada 29 Augustus 1982, 
Antonio mengaku suka dan betah tinggal di Semarang dari pertama kali dia mengunjungi Semarang untuk urusan bisnis property milik keluarganya.

Menurut Antonio dia tidak memerlukan banyak waktu untuk beradaptasi dengan lingkungan baru di Semarang.Pengalaman 4 tahun tinggal di Bandung dan 3 bulan sebelumnya menetap di Semarang sudah menjadi modalnya untuk bisa hidup bagus diSemarang. Masalah bahasa Indonesia, Antonio sudah berbahasa Indonesia dengan lancar sejak pertama datang ke Semarang. Masalah gaya hidup/lifestyle orang Semarang sudah sangat universal jadi tidak memerlukan usaha keras atau menemukan kesulitan yang berarti.

Hambatan yang paling sulit menurutnya adalah ritme kehidupan di dunia kerja. Menurutnya, memerlukan waktu lama untuk bisa masuk dan mengkombinasikan sistem kerjanya dengan pola kerja orang Semarang. Karena terpengaruh dengan budaya dasarnya sebagai seorang warga asing yang terkenal dengan budaya hard work dan on-time, time is money dan keteraturan jadwal hidup sangat susah diterapkan dengan orang lokal Semarang yang menurutnya terlalu lambat dalam bekerja, terkesan menyepelekan pekerjaan dan suka menunda-nunda pekerjaan, suka berkumpul dan ngerumpi di jam-jam kerja.

Pada awalnya hal ini sangat mengganggunya, dia harus marahmarah setiap hari dan bingung harus berbuat apa untuk karyawannya. Peraturan secara tertulis maupun lisan sudah dia sampaikan setiap hari dikantor, akan tetapi menurutnya ini adalah budaya dasar orang Jawa yang terbiasa dan terkesan 'nyantai' dalam pekerjaan. Kalau kata orang Jawa ada istilah 'alon-alon asal kelakon' yang berarti pelan-pelan asal terlaksana. Istilah ini tidak berlaku untuk bule, menurutnya time is money. Lebih cepat bekerja akan lebih baik dan menghasilkan uang yang banyak.

\section{Kesimpulan}

Penelitian ini membuktikan bahwa kendala utama komunikasi beda budaya mengenai perbedaan bahasa membuat para informan menggunakan beberapa cara untuk mempermudah beradaptasi dengan masyarakat lokal kota Semarang. Salah satunya dengan komunikasi non-verbal seperti menggunakan simbol-simbol, gerakan tangan, gerakan badan (gesture), dan juga mimik muka. Management meaning juga dipakai dalam proses adaptasi beda budaya antara expatriate dengan masayarakat lokal Semarang. Begitu juga yang terjadi dengan expatriate yang sudah fasih berbahasa Indonesia. Penggunaan idiom, aksen bahasa Indonesia yang berbeda, bahkan mother language dan bahasa Indonesia sehari-hari yang tidak lugas membuat expatriate merasakan kecemasan semakin besar, sehingga mudah terjadi pergesakan pengertian pesan yang diterima.

\section{Daftar Pustaka}

Alo Liliweri, 2007. Dasar-dasar Komunikasi Antar Budaya. Yogyakarta. Pustaka Pelajar

Deddy Mulyana. 2001. Metodologi Penelitian Kualitatif; Paradigma Baru Ilmu Komunikasi dan Ilmu Sosial Lainnya. Bandung: Remaja Rosdakarya 2005, Ilmu Komunikasi: Suatu Pengantar. Bandung: Remaja Rosdakarya.

Gunawan Witjaksana. 2005, PokokPokok Pikiran dalam Metodologi Penelitian Komunikasi Kualitatif. Buku ajar Ilmu Komunikasi. USM 
Jalaludin Rakhmat. 1994. Psikologi Komunikasi. Bandung: Remaja Rosdakarya.

Lexy. J. Moleong.2002. Metodologi Penelitian Kualitatif. Cet. 13 Bandung: Remaja Rosdakarya Littlejohn. 1999. Theories of Human Communication. Belmont, California: Wadsworth Publishing Company
Samovar. Larry A, Porter. Richard E, McDaniel. Edwin R2010. Komunikasi Lintas Budaya. (edisi terjemahan oleh Indri Margaretha Sidabalok). Jakarta. Salemba Humanika 